\title{
Selection Strategy of Combat-Oriented Teaching Mode for Radar Countermeasure Principle Course
}

\author{
He Huan, Pan Yi-chun, Peng Shi-rui, Geng Fang-zhi, Wang Guang-xue \\ Department of Information Countermeasures, Air Force Early Warning Academy \\ Wuhan 430019, China
}

\begin{abstract}
In order to choose a proper teaching mode and promote the combat-oriented teaching reform, this article divides the teaching contents of radar countermeasure principle course into four categories: basic knowledge class, knowledge application class, advanced technology class and knowledge extension class, and proposes the selection strategy of teaching mode according to content category. Wherein, the basic knowledge class adopts problem-based teaching, the knowledge application class adopts case teaching, the advanced technology class adopts seminar teaching, and the technology extension class adopts network teaching. Teaching practice shows that the reform of the course teaching mode has placed students in the dominant position of the class and effectively improves the teaching effect, and the selection strategy of teaching mode is highly operational and has important reference significance for the course of the professional background class.
\end{abstract}

Keywords-Radar countermeasure principle course; Combatoriented teaching mode; Selection strategy

\section{INTRODUCTION}

At the 2018 opening and training mobilization meeting, President $\mathrm{Xi}$ issued an order[1] to the whole army, calling on the whole army to carry out the new era Party's strong army thought, to strengthen the practical military training in an allround way and to improve the ability to win the war in an allround way. Military academies are indispensable components of actual combat training. Improving the level of actual combat teaching in military academies is to improve the level of actual combat training. In view of actual combat requirements, the construction of teaching mode plays an important role in drawing and guiding the unity of thinking, promoting teaching practice and improving teaching quality.

In the past 30 years, with the gradual deepening and opening of education reform, China's educational circles not only introduced a large number of advanced foreign teaching modes, but also created a large number of new teaching modes on the basis of the transformation of traditional teaching mode. In the face of such a rich and diverse teaching mode, which teaching mode should be selected and applied in view of actual combat requirements and course characteristics is a practical problem to be solved in the combat-oriented teaching reform. This paper puts forward that radar countermeasures principle course teaching should apply seminar teaching, case teaching, problem-based teaching and network teaching on the basis of lecturing teaching to promote the course combat-oriented teaching reform, and discusses the selection strategy of the above teaching modes in the course teaching.

\section{SYNOPSIS OF RADAR COUNTERMEASURES PRINCIPLE COURSE}

Radar countermeasure principle course is the main course of the professional background class for the trainees of growing cadres stipulated by the syllabus of Net-electric countermeasure intelligence analysis specialty in our academy. It mainly introduces the basic concepts, main methods and techniques of radar counter reconnaissance and radar jamming, and plays an important role in the follow-up equipment training and post job of the professional personnel. In 2012, the course was evaluated as a high quality course in the army. On this basis, the curriculum was promoted continuously, and a series of teaching achievements were achieved, but there was still a gap with the requirements of actual combat. Therefore, strengthening teaching reform and innovating teaching mode is the focus of curriculum construction under the background of actual combat.

The teaching mode serves the learning method, and the learning method follows the learning rule. In the field of educational psychology, there are four learning theories [2], namely behaviorism, cognitivism, humanism and constructivism. Although the standpoint and starting point of these learning theories are different, their understanding of learning is different, but they all reflect the basic rules of learning from different angles and horizons. It is the inevitable result of the choice and application of teaching mode to fully arouse the initiative and enthusiasm of the students and to highlight the main role of the students in the teaching activities.

The trainees of growing cadres come from different colleges, pointing to different units and posts. They generally have five characteristics. Firstly, the job demand is different. The students of the growing cadres come from different posts in different forces and have different concerns about the course learning. This requires that the teaching process should pay attention to the job demands of different posts. Secondly, the learning motivation is different. There are three kinds of motivation, which are positive, negative and conflicting. Thirdly, the starting point for studying is uneven. The trainees of growing cadres come from many different colleges, and their training environment is diverse and their majors are different. Fourthly, the character is lively and acute. The independent and open management mode of local colleges 
enables students to arrange the time according to their personal interests, which brings up the lively and acute thinking of the cadets and the curiosity and thirst for new technology and new knowledge. Fifthly, the concept of discipline is relatively weak. The trainees of growing cadres lack the experience of military life, are not ready for the hard life of the army, and have a relatively weak concept of organization discipline. The above characteristics of the teaching object require that the course group should fully consider the characteristics and needs of the students in the teaching reform, and choose the appropriate teaching mode to carry out the combat-oriented teaching.

Through the analysis of the characteristic advantages of the common teaching modes, the seminar [3], the case teaching [4], the problem-based [5] and the network [6] teaching mode conform to the psychological characteristics of the cadets. They can greatly mobilize the enthusiasm of the students, fully reflect the main body status of the students, give full play to the leading role of the teachers in the same time, and realize the positive interaction between students and teachers in teaching. They can stimulate students' creative thinking ability, cultivate their independent spirit and independent learning ability and scientific research ability, improve students' ability to discover problems, analyze problems and solve problems, and effectively improve students' information literacy. At the same time, in the continuous course construction, there are plenty of curriculum resources including a large number of military cases, network courses, and micro courses. Through the campus network, many learning platforms can be logged in, which can effectively support the classroom practice of discussion, case, problem and network teaching mode. Therefore, based on the relevant viewpoints of the learning theory, the radar countermeasures principle course teaching should apply seminar teaching, case teaching, problem-based teaching and network teaching on the basis of lecturing teaching. By creating a learning situation purposefully, the subjective initiative of the students can be exerts to a great extent, so as to achieve the purpose of strengthening the professional foundation of the students and improving the level of students' ability.

\section{StRategy of COMBAT-ORIENTED TEACHING Mode}

Choosing the teaching mode scientifically and rationally, we need to consider the teaching purpose, the content of teaching, the object of teaching, the conditions of teaching and the specialty of the teaching staff from the practical point of view. Next, from the perspective of teaching content, we consider the selection strategy of seminar teaching, case teaching, problem-based teaching and network teaching in the radar countermeasure principle course.

\section{A. The basic knowledge class adopting problem-based teaching and focusing on inspiration and guidance}

Problem-based teaching is a teaching mode which presents knowledge in the form of problems in front of students, let students learn knowledge, develop intelligence and develop skills in seeking and exploring problems, and cultivate students' ability to discover problems and solve problems. Problem-based teaching takes problems as the center to organize teaching, pays attention to enlightening guidance, and is conducive to training students' ability to discover, analyze and solve problems, to use learning resources, to cooperate and communicate with each other in the team.

In the "radar countermeasure principle" course teaching, the problem-based teaching mode is often adopted in the teaching content of basic knowledge. This part of the teaching content refers to basic theory, technical knowledge and so on. It belongs to the knowledge that needs to be firmly grasped by the students for laying a solid foundation for the follow-up courses. The basic concepts and principles of the first contact by students (such as "searching superheterodyne frequency measurement technique", "RF noise jamming", etc.), emphasizing the acceptance and internalization of knowledge, may adopt the heuristic method of problem-based teaching which takes lecture as the basic form, to deepen the understanding of the students and improve the efficiency of the classroom teaching. The principle class knowledge that can be analogous to the prior knowledge of the course (such as that "beam searching direction measurement technique" can be analogous to "searching superheterodyne frequency measurement technique", etc), which is suitable for students to learn and discover autonomously on the basis of previous knowledge, may adopt the discussion method of problem-based teaching which takes discussion as the basic form, to effectively stimulate students' problem awareness, help students understand the knowledge points comprehensively and correctly, train students' thinking, and achieve effective teaching.

\section{B. The knowledge application class adopting case teaching and highlighting key points}

Case teaching means that the teaching staff, in accordance with the purpose of combining theory with practice, follows the requirements of teaching purposes, takes cases as the basic material, introduces students into a real situation of a particular event, trains students' critical reflection awareness and group cooperation ability, and promote the students to fully understand the complexity, variability and diversity of the learning problems via interaction, dialogue and discussion among teachers and students. The case used in case teaching is typical, which comes from practical problems in army equipment utilization and combat training. Through learning and analyzing a case, from point to area, students can master the analysis and solution of a class of problems and improve their post competency.

In the "radar countermeasure principle" course teaching, the case teaching mode is often adopted in the teaching content of knowledge application. This part of the teaching content refers to the theory, technology and method which are closely connected with the practical problems of the operational application of radar counter equipment or the military combat training. It belongs to the knowledge that needs a profound understanding for meeting the job requirements of the post. These contents emphasize military application, and case teaching mode can be adopted. For example, the calculation of radar counter reconnaissance distance and analysis of influence factors can be discussed in combination with a certain type of UAV attack target in a rehearsal, the effective interference space calculation and the analysis of influence factors can be 
discussed in combination with the route planning problem of a certain type of jammer in a rehearsal. With the help of cases in military practice, the case teaching mode provides students with broad thinking space and the situation similar to "actual combat", guides cadets to discuss the specific and difficult problems hidden in them so as to achieve the goal of cultivating students' creative thinking and improving their ability to solve practical problems.

\section{The advanced technology class adopts seminar teaching and constructing cognitive structure}

Seminar teaching means the students, under the guidance of the instructors, on the important and difficult issues in the teaching or the subject with the nature of research, through independent study and discussion together, independently carry out the concept construction, understand and discover the laws, and finally get the correct conclusions to acquire knowledge and enhance their ability. Seminar teaching is conducive to the deep understanding of knowledge, and is conducive to the cultivation of students' ability of deductive thinking, and is conducive to the cultivation of students' scientific spirit and innovative ability.

In the "Radar countermeasure principle" course teaching, the seminar teaching mode is often adopted in the teaching content of advanced technology. This part of the teaching content is closely related to the contents of the academic research frontiers which emphases scientific research, such as new technology and development trend of radar reconnaissance and radar jamming, new algorithm of radar signal sorting, radiation source identification and intra pulse feature analysis, etc., and seminar teaching mode can be adopted. Seminar teaching takes research and discussion as the starting point, uses the interactive principle of teaching and learning, gives full play to the leading role of the teachers and the main role of the students, lets the students actively participate in the research and discussion, and cultivate the students' innovative consciousness, creative thinking and creative ability.

\section{The technology extension class adopting network teaching based on resource sharing}

Network teaching means the use of network technology as an organic factor to form a new learning environment. It takes the inquiry learning as the main way of learning, with the main realization methods of MOOC, network course, WEB teaching material, multimedia courseware, BBS forum and so on, to realize remote, simultaneous, real time, interactive teaching and learning. Network teaching has the characteristics of resource sharing, space-time ductility, multi direction interaction, learning cooperation, independent selectivity and so on. It is beneficial to embody the subject status of students' study, meet the individualized requirements of students, cultivate students' good information literacy, and realize full education and lifelong education.

In the "Radar countermeasure principle" course teaching, the network teaching mode is often adopted in the teaching content of knowledge extension. The effective development of network teaching depends on the gradual construction of the information teaching platform and methods, and relies on the development and improvement of the related network courses and teaching resources. At present, the curriculum has the basic teaching conditions for developing network based teaching. In order to broaden the knowledge of the students and improve their enthusiasm for learning, the network teaching mode can be adopted in the teaching of the extension knowledge of the course content, such as the analysis of the typical combat examples in electronic warfare and the radar stealth technology, etc. In addition, network teaching can be used for students to arrange their own learning activities and to supplement and improve their own knowledge system. It can also be used as a supplement and expansion of current teaching, and for students to carry out micro learning with pertinence and checking based on the related teaching resources. It can be used to realize the imparting and internalization of knowledge based on an upside down arrangement of knowledge.

\section{CONCLUSION}

In this paper, the teaching content of the "Radar countermeasure principle" course is divided into four categories: basic knowledge class, knowledge application class, advanced technology class and knowledge extension class, and the strategy of selecting and applying the practical teaching mode according to the teaching content is put forward. Thereinto, the basic knowledge class adopts problem-based teaching, focusing on inspiration and guidance. The knowledge application class adopts case teaching, highlighting point to area. The advanced technology class adopts seminar teaching, constructing cognitive structure. The technology extension class adopts network teaching, based on resource sharing. From the recent students' feedback, the reform of the course teaching mode has implemented the main position of the students, changed the students' learning form and effectively improved the teaching effect. The information feedback from the experts and peers showed that the strategy of selecting the teaching mode according to the teaching content is more operational for the proper use of the combat-oriented teaching modes, and has important reference significance for the course of the professional background class.

\section{REFERENCES}

[1] "XI Jin-ping issued instructions to the PLA" [R]. Liberation Army Newspaper, January 4, 2018 (In Chinese).

[2] ZHANG Da-jun. Educational Psychology (3rd ed.) [M]. People's Education Press, 2015: 65-99 (In Chinese).

[3] WANG Guang-xue, HE Huan, PENG Shi-rui, GAO Wan-xia. "Application of research-and-discussion teaching method in the "radar counter measure technology and experiment" course" [J]. Technology Innovation Guide, 2016, 32: 159-160 (In Chinese).

[4] LIU Shi-hua, HU Bing, ZHANG Xian-zhi. "Method of military case teaching in course of radar position optimization" [J]. Journal of Air Force Early Warning Academy”, 2017, 31 (1): 64-66 (In Chinese).

[5] HE Huan, PAN Yi-chun, GENG Fang-zhi, ZOU Xiong. "Teaching method of problem-discussion in radar countermeasure technology and experiment course" [J]. Journal of air force early warning Institute, 2016, 30 (6): 460-463 (In Chinese).

[6] YANG Cheng-li, KONG Jin-ming, LI Da-li, SHI Ruo-fu, FAN Yanrong. "Exploration of MOOC video application and flipped classroom teaching practice" [J]. Higher Education Journal, 2018, 3: 106-107(In Chinese). 